\title{
Overview of Trigger Film Strategies
}

Linc. Fisch

Jack: [Offering wine bottle.] Want some?

Tim: No.

Jack: Scared? [Bottle still held out.]

Tim: I ain't scared...

Jack: Catch it or it'll break!

[He drops it. Tim's hands catch it, hold it tight.]

Now you drink!

[Freeze on Tim's hands holding bottle. Cut.]

The above excerpt is from the script of "The Buddies," a trigger film about two 10-year-old boys. It's one in a series of six alcohol education films developed for the National Institute on Alcohol Abuse and Alcoholism. They don't lecture or moralize. They are designed to help young people decide for themselves about the use of alcohol.

The excerpt actually represents nearly half of the film. Short? Extremely so-trigger films often are only a minute long. Dramatic? Quite - every shot in "The Buddies" is a close-up. Incomplete? Intentionally -the essence of a trigger film is its open-endedness. All of these are calculated to enhance the purpose of a trigger film: to trigger feelings and reactions of the viewers.

A trigger film can do more than produce rapid entry into a discussion. When group members work first with a relatively unthreatening situation simulated in a film, they often become more free to discuss parallel situations in their own lives. Since participants begin to use each other as resources, the technique facilitates movement of 
the teacher out of an authority role, which enhances learning in many circumstances.

This unique kind of film-for-discussion evolved in 1968 at The University of Michigan Television Center with a series of films produced for training young drivers. The imnovation caught on rapidly, and trigger film series have been produced for use in such diverse fields as aging, drugs, mental retardation, nutrition, smoking and health, patient education, learning-teaching and library media utilization. One indication of how extensively the trigger film idea has spread: As of this writing, there are 25 trigger films relevant to the field of alcohol education alone.

The small-group discussion is the basic trigger film strategy. Trigger films have been used widely in classroom discussions at all educational levels and in seminars at meetings and conferences, including the 1971 White House Conferences on Aging. The technique also has been incorporated into several other instructional strategies.

\section{Variations in Use}

Because a trigger film is so compact, the production of a trigger film can readily become the focal activity in a groups' learning experience. This strategy was employed beautifully in a high school sex education seminar: Students developed ideas, prepared a script, acted out roles, filmed and edited -all the while going through a very meaningful exploration of the dimensions of human sexuality. A similar approach, using videotape instead of film, is being used successfully for in-service training of teaching fellows and peer counselors at the University of Michigan.

A variation of the production strategy has been adapted for workshops at several regional and national public health conferences. The medium of videotape permits compressing the production time and allows for instant replay. Production can be accomplished with a portable, one-camera video system that can be carried easily by one person. In one notable instance of the learning effectiveness of this strategy, 40 public health workers in Texas produced five trigger tapes on smoking and health in a little over two hours. 
The results were quite acceptable for showing at a booth during the remainder of the conference, but the primary achievement was that the workshop members examined the parameters of smoking and health, developed increased awareness of exemplary health behavior, and in many cases came to firmer commitments themselves with regard to such behavior.

Although trigger films are clearly intended for use in group learning experiences, there is at least one instance of a trigger film being used in a one-on-one situation. A film focusing on the nature and cause of alcohol abuse was developed for training case workers in a county health department. Several of the case workers began to use the film in individual consultation because it allowed moving easily from exploration of the film situation to examination of the client's own problem.

A program developed by the U.S. Army at Fort Knox is another practical example of a trigger film strategy at work. Video trigger tapes of problem racial situations are shown; the tapes end at the height of the critical moments for decision making or action. Viewers then play out the roles from that point and in the process explore and begin to resolve some of their own tensions with regard to interracial relations.

Since a trigger film never stands alone-discussion is a mustpublic television applications ordinarily are not appropriate. However, one producer is incorporating trigger film will be shown to a group of teenagers and to a group of adults. By frequent cutting from one discussion to the other, comparisons of attitudes in the two age groups will be portrayed. In a sense, viewers of the program will be participating in both discussions vicariously.

Perhaps one of the more unusual variations of trigger film strategy is occurring at the UK College of Dentistry. In a curriculum that extensively employs self-instructional modules, Oral Biology faculty members have observed that a relatively unvaried instructional diet sometimes contributes to student lethargy. Trigger videotapes related to the modules are being programmed intermittently to rekindle motivation and interest and to stimulate discussion and interaction among students.

The preceding instructional strategies share one thing in common: the use of a film or video tape to trigger viewer interaction. The 
interaction is the essential ingredient for learning; the film or tape is a highly effective way of bringing it about.

Strategies for using trigger films are appropriate only if interaction among persons is an indicated method for achieving instructional goals. Some general examples of goals in this category are affecting attitudes, clarifying values, modifying perceptions and generating commitments.

In a university setting, trigger film strategies might be applicable in areas where the primary focus is on issues - for example, behavioral sciences, social professions, law, teacher education. They may also be applicable in training for more effective interpersonal skills-interviewing, counseling, academic advising, patient relations, to mention a few areas. They may be employed for training in problem solving and decision making in management courses. And in almost any area they can be used to energize students.

While trigger film strategies have wide applicability, they should be used judiciously in a mix with other instructional strategies. As important as when and why to use a trigger film is the matter of how to use it wisely. Proper discussion management is an important consideration. A very good trigger film can be made completely ineffectual by imposing constraints, control or evaluation on the interaction that develops from the film.

\section{Production}

When examining trigger films and trigger tapes, certain characteristics are frequently found: limited data presented, open-endedness, relative incompleteness, and an emotional aspect. These features are deliberately built into the films in order to generate rapid viewer involvement. The viewer quickly begins to work with the feelings and tensions that are being experienced, to hypothesize about missing data, and to look for interrelations among aspects of the situation in an attempt to construct a more understandable whole.

In the design of a trigger film, the primary consideration is identification of educational goals, as it is in any instructional problem. The next consideration is development of a situation that will generate attention to the area of the objective. The point at which to enter the 
situation and the extent to which data can be omitted are very significant, since brevity seems to heighten the impact of a trigger film. Often, reduction of dialogue enhances effectiveness.

Of all the decisions that are necessary in a trigger film production, the most critical is determination of where to terminate the film for optimal triggering of viewer interaction. Trigger film producers often ask themselves, "What immediate response do I want from the group when the projector is stopped?" Generally, closure is to be avoided. Alternatives and dilemmas may be posed, but the action should stop short of decision. The idea is not to present solutions, but to create a context in which people explore ideas, examine alternatives and reach their own decisions.

People frequently become interested in developing their own trigger films, but are concerned about the cost. A professionally produced $16 \mathrm{~mm}$ trigger film of a minute or two in length can cost $\$ 2000$ or more. Obviously, costs such as this would be justified only if extensive use or wide distribution were distinct possibilities. The cost might be cut to less than half by using color videotape instead of film. (At a moderate additional expense, a video trigger tape could be transferred to film, if the latter were the required display format.)

For the average academic department which finds several hundred dollars a prohibitive expenditure, there are other alternatives. For many in-house uses, very satisfactory trigger films can be produced with $8 \mathrm{~mm}$ film or videotape using portable equipment; film and tape costs are low, and not a great deal of time or experience is required. And the really creative person (who, after, all, is a more essential production ingredient than money) may be able to accomplish almost the same results with $35 \mathrm{~mm}$ slides and synchronized audio tape for, perhaps, as little as $\$ 5$ out-of-pocket.

To be sure, saving on cost always involves trade-offs. IN a $\$ 2000$ film production there can be flashy titles, jazzy effects, beautiful sound, a luxurious ratio of film shot to film used, and dramatically tight edits. Some of these may have to be sacrificed when using videotape, but less time in production is a compensation. Even though most of them are apt to be missing from the $\$ 5$ version, a properly conceived economy model may do the job quite well for the individual teacher in the individual classroom. The prime criterion for the evalu- 
ation of a trigger film is not whether it wins film festival awards but whether it triggers response. If it does, it will be successful.

The choice of an instructional strategy is also a pragmatic one: will it accomplish the desired results? Trigger film strategies are often useful when the goals are behavioral and attitudinal changes brought about by group interaction. If this is what you are trying to achieve, then trigger films may be an innovation you want to consider.

Further information on trigger films and their use can be found in these articles.

\section{Bibliography:}

Fisch, A.L., "The Trigger Film Technique," Improving College and University Teaching. Vol. XX, No. 4, Autumn 1972, pp. 286-289.

Miller, E.J., "Trigger Filmmaking," Audiovisual Instruction, May 1971, pp. 64-67.

Miller, E.J., "The Trigger Film Triggers Response," Audio Visual Instruction, October 1968, pp. 876-880. 